\title{
DESENVOLVIMENTO DE UM BIOPOLÍMERO DE FÉCULA DE MANDIOCA PARA ISOLAMENTO TÉRMICO
}

\author{
E. M. D. ALCÂNTARA', J. U. L. MENDES ${ }^{2}$ \\ Universidade Federal do Rio Grande de Norte - UFRN \\ ellison.matheus@gmail.com
}

Submetido 31/10/2018 - Aceito 29/11/2018

DOI: $10.15628 /$ holos.2018.6217

\section{RESUMO}

As preocupações ambientais vêm aumentando nos últimos anos, principalmente devido ao uso de vários produtos derivados de petróleo, os quais levam anos para se degradar na natureza. Para minimizar esse problema, vários estudos focam na utilização de materiais naturais biodegradáveis. Nesse contexto, verificou-se que a fécula de mandioca pode ser aproveitada como matéria prima para produção de um biopolímero que pode ser utilizado como isolante térmico. O biopolímero foi produzido por um processo de expansão térmica controlada com frações volumétricas de $30 \%$ de água e $70 \%$ de fécula de mandioca. Foram analisadas as propriedades físicas e térmicas do material com intuito de obter dados sobre a viabilidade de seu uso como isolante térmico. O material apresentou uma condutividade térmica de 0,152 W/mK, podendo ser aplicado como isolante em sistemas quente de até $270{ }^{\circ} \mathrm{C}$ e um limite de resistência a temperatura de $270{ }^{\circ} \mathrm{C}$ observado pela análise termogravimétrica. $\mathrm{O}$ biopolímero de fécula de mandioca mostrou-se eficiente quanto à isolação térmica, devido possuir propriedades semelhantes às de isolantes térmicos disponíveis comercialmente. Além disso, foram realizadas análises de inflamabilidade, a qual o material se apresentou como não inflamável. Além disso, analisou-se dureza caracterizando-o como um material duro. Diante disso, o material mostrou-se promissor a ser aplicado como isolante térmico. Essas análises foram fundamentadas em normas ABNT, ASTM e UL-94 e os resultados obtidos experimentalmente comprovam que o biopolímero de fécula de mandioca pode ser utilizado para fins de isolamento térmico.

PALAVRAS-CHAVE: Biopolímero, fécula de mandioca, biodegradável, isolante térmico.

\section{DEVELOPMENT OF A BIOPOLYMER OF CASSAVA STARCH FOR THERMAL INSULATION}

\begin{abstract}
Environmental concerns have been rising in recent years, mainly due to the use of various petroleum products, which take years to degrade in nature. To minimize this problem, several studies focus on the use of natural biodegradable materials. In this context, it has been found that cassava starch can be used as raw material for the production of a biopolymer that can be used as a thermal insulation. The biopolymer was produced by a controlled thermal expansion process with volumetric fractions of $30 \%$ water and $70 \%$ cassava starch. The physical and thermal properties of the material were analyzed in order to obtain data on the feasibility of its use as thermal insulation. The material had a thermal conductivity of $0.152 \mathrm{~W} / \mathrm{mK}$, and can be applied as an insulator in hot systems up to $270^{\circ} \mathrm{C}$ and a temperature resistance limit of $270^{\circ} \mathrm{C}$ observed by
\end{abstract}

thermogravimetric analysis. Cassava starch biopolymer proved to be efficient in thermal insulation, due to its properties similar to those of commercially available thermal insulators. In addition, flammability analyzes were performed, to which the material presented as non-flammable. In addition, hardness was analyzed by characterizing it as a hard material. In view of this, the material proved promising to be applied as a thermal insulation. These analyzes were based on ABNT, ASTM and UL-94 standards and the results obtained experimentally prove that the biopolymer of cassava starch can be used for thermal insulation purposes.

KEYWORDS: Biopolymer, cassava starch, biodegradable, thermal insulation. 


\section{INTRODUÇÃO}

É perceptível a degradação ambiental causada pelas indústrias, principalmente pelo uso de materiais impróprios (RIYANJAN; PATISAT, 2018). Por isso, hoje há um grande interesse nas pesquisas que desenvolvam tecnologias baseadas em recursos naturais às quais possuam capacidade de degradação elevada sem gerar resíduos tóxicos. Atualmente, com essas preocupações ambientais, as indústrias têm buscado materiais que não degradam o meio ambiente e sejam de baixo custo. Diante disso, há um aumento de estudos em aplicações das fibras vegetais, as quais podem substituir as sintéticas, além disso, os polímeros naturais, que também podem substituir os polímeros sintéticos (ÁVEROUS; DIGABEL, 2006).

O desenvolvimento de produtos a base de polímeros naturais, biopolímeros e/ou biodegradáveis estão oferecendo diversas alternativas em busca de um processo de desenvolvimento mais sustentável (Abd El-Rehin, 2006; Ma el al., 2012). Entre esses materiais, a fécula de mandioca vem sendo bastante estudada na produção de materiais biodegradáveis, que também pode ser conhecida como amido de mandioca, polvilho doce ou goma de mandioca. Ela é caracterizada por possuir um pó fino, branco, inodoro e insípido. Esse produto pode ser adquirido através das raízes da mandioca, depois de seu descascamento, trituração, desintegração, purificação, peneiramento, centrifugação, concentração e secagem. O Brasil possui uma produção desse material em larga escala, tendo o Pará como maior produtor brasileiro, contribuindo cerda de 70,5 \% da produção nacional. (DEBIAGI et al., 2013).

O amido de mandioca tem sido aplicado industrialmente na produção de espumas (expandidos), filmes, sacolas e ainda itens de higiene pessoal. Esse material tem sido usado, principalmente, no desenvolvimento de embalagens biodegradáveis, com objetivo de substituir as embalagens sintéticas por produtos que são ambientalmente corretos (BRITO et al., 2011).

Perotti et al. (2017) desenvolveu Nanocompósitos orgânicos-inorgânicos à base de amido de mandioca, glicerol e veios de argila modificados com quitosana em duas diferentes relações (2,5 e 5,0\% em peso). Esses foram preparados por extrusão produzindo plásticos flexíveis, transparentes e homogêneos. Foi verificado que houve uma melhoria significativa de mais de $20 \%$ na resistência à tração e no módulo de Young, observadas para amostras contendo argila modificada com quitosana em comparação com amido termoplástico puro (Termoplástico de fécula de mandioca).

Foram desenvolvidos compósitos que utilizaram como matriz a espuma de fécula de mandioca, as quais são obtidas por extrusão e termoprensagem, com frações volumétrica de $80 \%$ de amido, $19 \%$ água e $1 \%$ de plastificante (glicerina). Além disso, foram usadas algumas fibras naturais como reforço com intuito de analisar comparativamente a influência das propriedades do compósito com o aumento da fração volumétrica de fibra. O material que não incorpora fibra (espuma de fécula de mandioca) apresentou uma maior resistência a compressão, $35 \mathrm{~N}$ e flexibilidade de $5 \mathrm{~mm}$, aproximadamente. Essas propriedades desse material são de extrema importância no desenvolvimento de compósitos, pois ele pode ser usado como matriz (NAIME et al., 2012).

Ramírez et al. (2011) desenvolveu um compósito que usa fécula de mandioca como matriz e fibra da casca do coco como reforço, percebendo-se que com o aumento da fação volumétrica da 
fibra está relacionado diretamente com a elevação da resistência mecânica do material. Além disso, foram realizados estudos das propriedades mecânicas, apenas da matriz de fécula de mandioca, a qual obteve como resultados curvas típicas de matrizes (com e sem tratamento térmico), observando que a fécula de mandioca apresenta grandes deformações e baixa resistência.

Segundo Stoffel et al. (2015), desenvolveu bandejas de espuma de amido de mandioca por meio de expansão térmica. Foram realizadas análises de suas morfologias, propriedades físicoquímicas e mecânicas. Além disso, foi analisada a diferença de bandejas com e sem microcelulose. Em relação a densidade as duas obtiveram praticamente os mesmo resultados (em média $0,25 \mathrm{~g} / \mathrm{cm}^{3}$ ). Enquanto a absorção de água foi visível que é proporcional ao tempo e que após 60 minutos ambos os materiais obtiveram a mesma absorção, cerca de $300 \%$. Já as propriedades mecânicas também não foram influenciadas significativamente com a adição de $1 \%$ de microcelulose, obtendo como resultado médio: resistência à tração de 0,61 Mpa e um alongamento de $0,45 \%$.

A fécula de mandioca, também conhecida como amido de mandioca, possui ampla aplicação nos setores alimentícios aonde vem sendo usado há anos. Cada vez mais, cresce o interesse pelo desenvolvimento de novos materiais, especialmente os biodegradáveis, fazendo com que aumente o número de trabalhos referente ao uso dessa matéria prima como principal componente na criação de novos produtos. Nota-se que os materiais desenvolvidos a partir de fécula de mandioca e água possuem características físicas de espumas, as quais são ótimas em isolamento térmico. Dessa forma, o objetivo deste trabalho é desenvolver um biopolímero que utiliza fécula de mandioca e água para ser aplicado em isolamento térmico. O mesmo é motivado pela possibilidade de desenvolver um isolante térmico de caráter inovador.

\section{METODOLOGIA}

\subsection{Fabricação do biopolímero}

Na fabricação do biopolímero foi usada como matéria prima a fécula de mandioca e água. A fécula de mandioca (Figura 1a) foi adquirida em feiras livres na cidade de Natal/RN, enquanto a água usada foi destilada no Laboratório de Mecânica dos Fluidos - NTI/UFRN. Além desses materiais, foi necessário o uso de um antidesmoldante (Figura 1b) com objetivo de facilitar a retirada do material do molde, esse foi adquirido na loja Hidro Glass localizada em Natal/RN. Com o objetivo de evitar impurezas que possam interferir nas propriedades do biopolímero, foi usada água destilada a qual foi adquirido através de um destilador, mostrado na Figura 2.

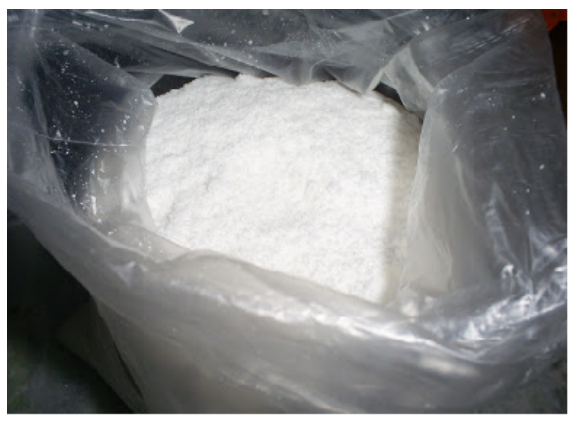

(a)

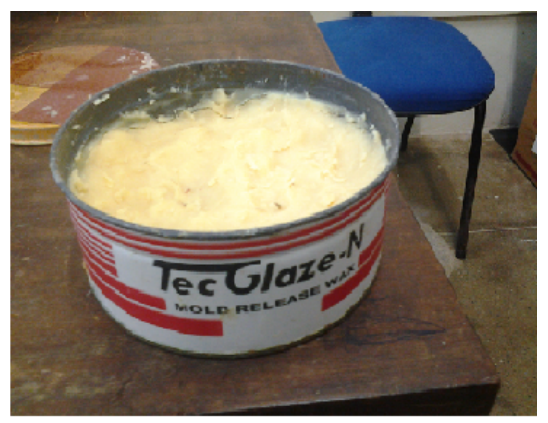

(b)

Figura 1: Materiais usados na fabricação - a) fécula de mandioca; b) antidesmoldante 


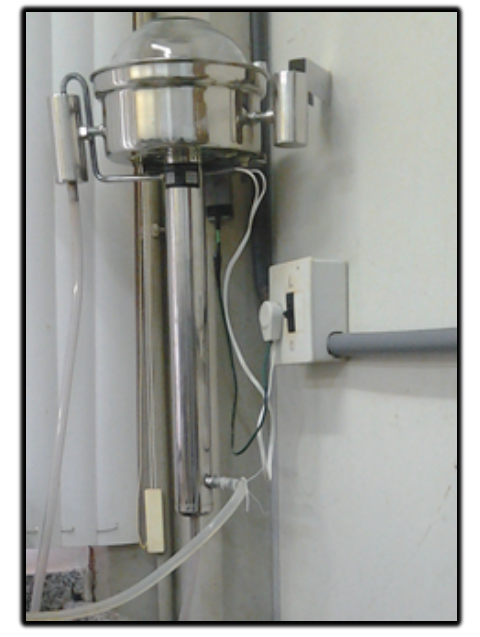

Figura 2: Destilador

O processo de fabricação definido para o desenvolvimento do biopolímero de fécula de mandioca (espuma de fécula de mandioca) é o de expansão térmica, o qual é realizado da seguinte forma, os dois materiais (fécula e água) são misturados manualmente em um béquer em seguida vertido no molde. Após isso, é levado ao forno com temperatura controlada de forma que ocorra a expansão espontânea do material, deixando-o na forma de uma espuma natural.

A proporção ideal encontrada para o material foi de $70 \%$ de fécula e $30 \%$ de água, além de uma temperatura de $250^{\circ} \mathrm{C}$. Essas variáveis apresentaram um melhor resultado, sendo possível desenvolver uma espuma bem distribuída, compacta e leve. Enquanto que os materiais com proporções menores de água tiveram seu manuseio dificultado devido à alta viscosidade da mistura, além de apresentarem uma baixa expansão, já os de maiores proporção, apresentaram grande quantidade de vazios e paredes muito fina. Esses problemas dificultaria uma possível quantificação de suas propriedades. Portanto, definiu-se a proporção ideal de $70 \%$ de fécula e $30 \%$ de água.

Após o tempo de permanência no forno, ocorre à expansão controlada do material. Após esse procedimento, a espuma de fécula de mandioca é esfriada no forno durante 24 horas, com objetivo de evitar possíveis choques térmicos e homogeneizar sua estrutura. Portanto, ao fim do processo, o biopolímero se tornou uma espuma porosa, leve, e rígida, a qual é apresentada na Figura 3.

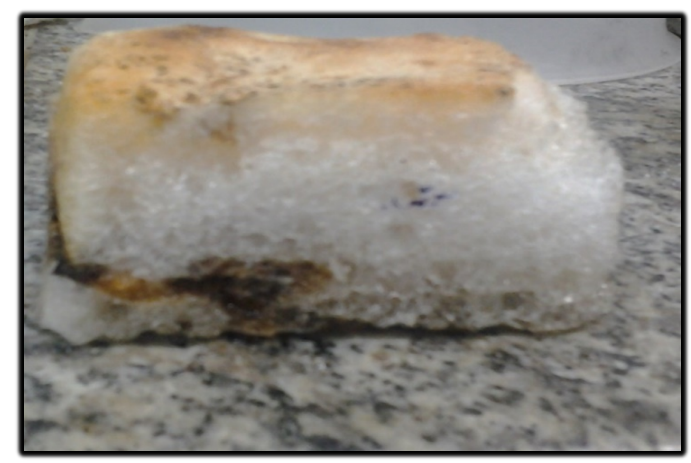

Figura 3: Biopolímero de fécula de mandioca 


\subsection{Determinação da massa específica}

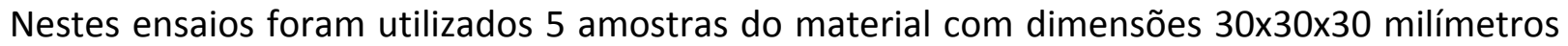
(Figura 4a), de acordo com prescrições da ASTM D 792 (2008).

Para realização do ensaio, as amostras foram cortadas com objetivo de deixa-las com as dimensões padrões. Em seguida o densímetro passa pela sua calibração a qual usa um béquer com água destilada (densidade da água $1,05 \mathrm{~g} / \mathrm{cm}^{3}$ ) e sensor de temperatura. Após isso, a amostra é levada a prato da balança, onde é realizada a pesagem da amostra (massa seca), como observado na Figura 4b. Em seguida, a amostra é submersa na água contida no béquer através de um cesto convexo (massa molhada), como observado na Figura 4c. Diante desses dados, pelo principio de Arquimedes, a balança apresenta o resultado da densidade do material em $\mathrm{g} / \mathrm{cm}^{3}$.

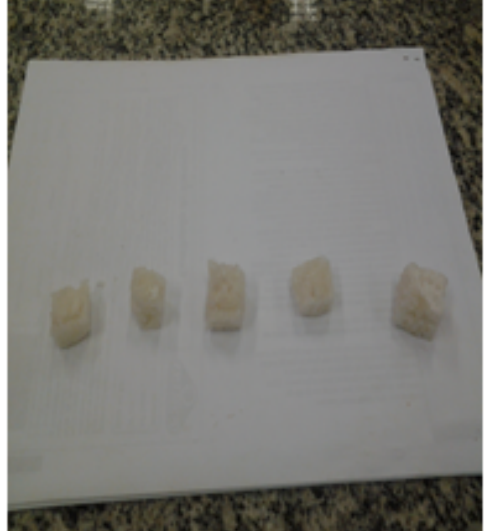

(a)

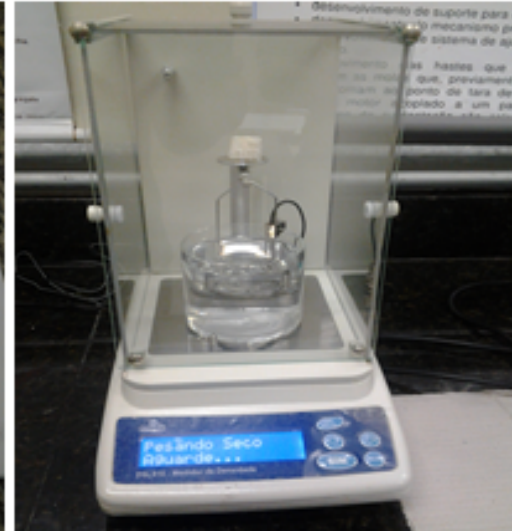

(b)

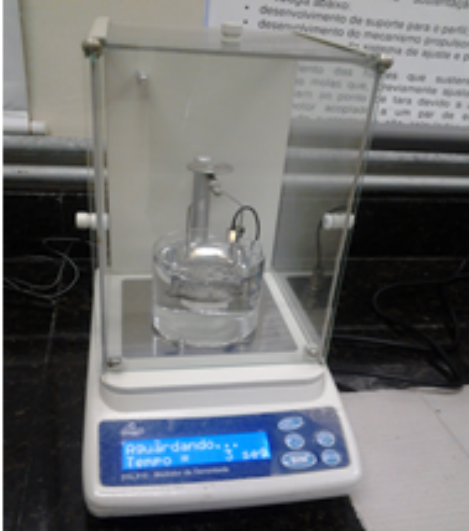

(c)

Figura 4: Massa específica do material - (a) amostras; (b) pesagem no prato; (c) amostra submersa

\subsection{Determinação do calor específico, condutividade térmica e difusividade térmica}

Esses ensaios permitem determinar as propriedades térmicas do material. Com isso foi utilizado o equipamento KD2 Pro (Figura 5a), disponível no laboratório de mecânica dos fluidos NTI / UFRN, o qual possui um sensor SH-1 (agulhas térmicas duplas) que serve para capturar valores após 2 minutos de inserção nos corpos de prova, esse sensor trabalha na faixa de 0,02 a $2,00 \mathrm{~W} / \mathrm{m}-\mathrm{K}$.

Foram realizados furos no material utilizando uma furadeira de bancada, a qual utilizou uma broca de 2 polegadas de diâmetro. Esses furos foram realizados em pares, com espaçamento necessário para que os sensores do equipamento penetrassem no material, como observado na Figura 5b. Essas agulhas (sensores) apresentam comprimento de $30 \mathrm{~mm}$ e diâmetro de 1,27 mm e o principio de funcionamento do equipamento é, basicamente, a criação de um fluxo de calor entre essas agulhas. Dessa forma, o equipamento apresenta os resultados das propriedades térmicas do material.

Os ensaios foram realizados de acordo com o manual do fabricante do equipamento. Diante disso, foram analisados 4 corpos de prova com dimensão de $120 \times 7 \times 5$ milímetros, para cada um desses foram feitas 3 medições em pontos distintos. Observa-se na Figura $5 b$ o ensaio sendo realizado. 


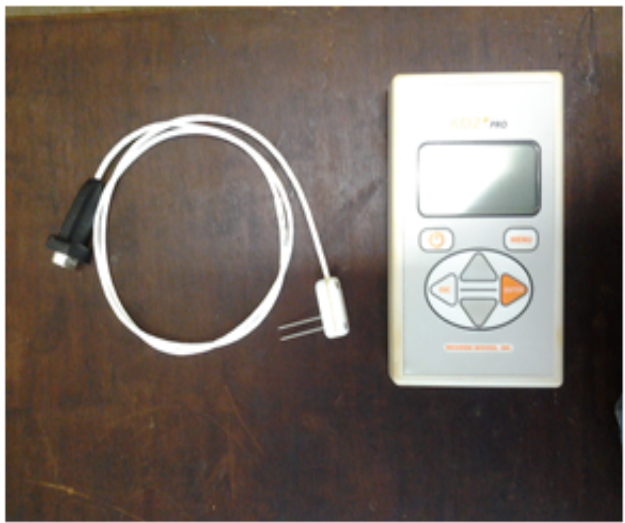

(a)

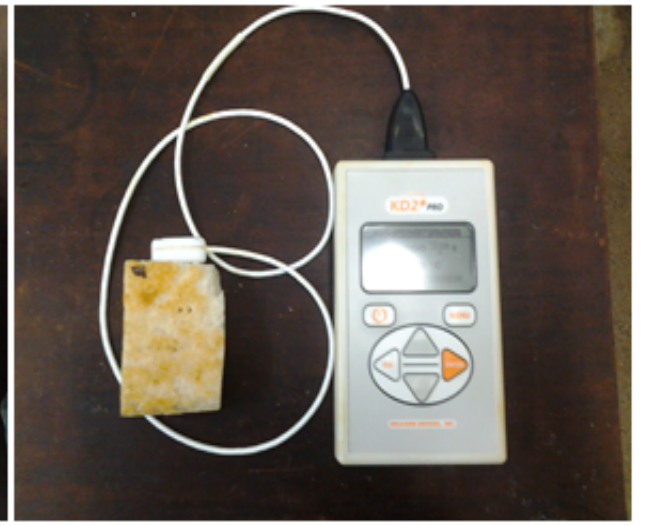

(b)

Figura 5: Análise térmica - a) equipamento KD2 PRO; b) ensaio

\subsection{Ensaio de dureza}

A dureza de um material expressa a sua resistência às deformações permanentes, a qual pode ser mencionada como a capacidade de um material penetrar outro. Essa propriedade está diretamente relacionada com a força de ligação dos átomos do material. Além disso, o termo dureza também pode está associada à resistência a flexão, risco, abrasão ou corte.

Os ensaios de dureza deste trabalho foram realizados no Laboratório de Tribologia e Dinâmica - NTI/UFRN, utilizando um Durômetro Analógico Portátil Shore D da Kori Seki MFG. Co. LTD (Japão), mostrado na Figura 6a. De acordo com a norma ASTM D 2240 (2003), Esse equipamento é indicado para medições de dureza de borrachas, plásticos e espumas que sejam rígidos, a qual sua medição se dá pela pressão de um penetrador de aço sobre o corpo de prova. Neste ensaio, utilizou-se 4 corpos de prova com dimensões 100×50×30 milímetros.

Foram realizadas 4 medições, em diferentes pontos, em cada corpo de prova. A Figura 6b mostra a execução do ensaio.

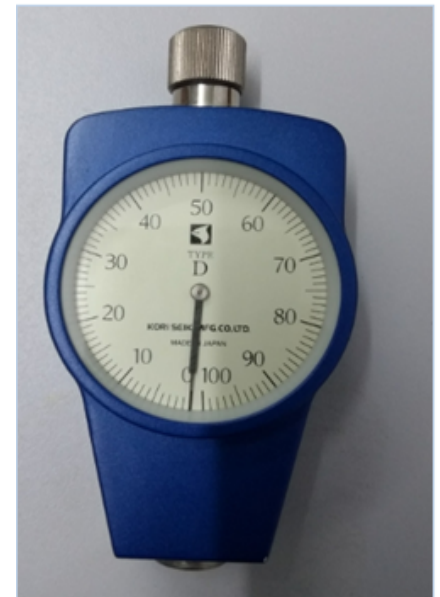

(a)

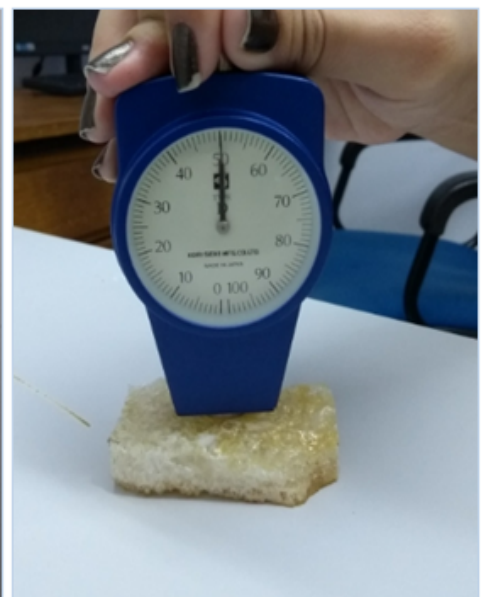

(b)

Figura 6: Ensaio de dureza - a) durômetro Shore D; b) Ensaio em execução 


\subsection{Análise termogravimétrica - TGA}

A termogravimetria (TG) é a técnica na qual a massa de uma substância é medida em função da temperatura, enquanto a substância é submetida a uma programação controlada de temperatura. Essa técnica consiste basicamente em uma balança de alta precisão associada a um forno, no qual se pode controlar a taxa de aquecimento (em geral de $10{ }^{\circ} \mathrm{C} / \mathrm{min}$ ) ou manter a temperatura constante. A atmosfera à qual a amostra é submetida também pode ser controlada.

Neste trabalho realizou-se analises termogravimétrica em 2 amostra do biopolímero de fécula de mandioca, as quais possuíam massa de $10 \mathrm{mg}$. As análises foram realizadas através do equipamento Analisador termogravimétrico e calorimétrico simultâneo modelo NETZSCH TG209F1 Libra, disponível no laboratório de Análises térmicas do Instituto de Química/UFRN. De acordo com a norma ASTM D6370, as amostras foram colocadas em cadinho de alumina e submetidas a temperaturas que variaram da ambiente até $700^{\circ} \mathrm{C}$, com uma taxa de aquecimento de $5^{\circ} \mathrm{C} / \mathrm{min}$ em atmosfera de $\mathrm{Ar}$, com vazão de $20 \mathrm{ml} / \mathrm{min}$.

\subsection{Microscopia eletrônica de varredura - MEV}

A técnica da microscopia eletrônica de varredura (MEV) permite uma observação das amostras ampliada em muitas vezes com uma boa resolução de imagens, proporcionando a caracterização morfológica do material em análise.

Para a realização do ensaio, utilizou-se 3 amostras do biopolímero de fécula de mandioca com

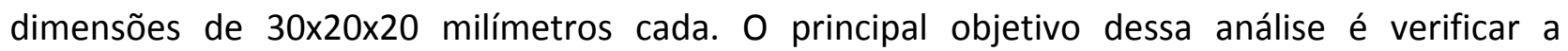
porosidade e as características morfológicas do material.

As análises foram realizadas no em um microscópico eletrônico de varredura (MEV), marca HITACHI, modelo TM3000. As amostras foram encaminhas ao Laboratório de Caracterização Estrutural de Materiais DEMAT/UFRN, onde foram fixadas sobre na porta amostra metálica através de uma fita de carbono. Em seguida as amostras foram dispostas no equipamento e então foram realizadas as análises.

\subsection{Ensaio de inflamabilidade}

Neste trabalho os ensaios de inflamabilidade foram realizados de acordo com a norma UL94, que orienta a realização dos ensaios através do método UL94 HB (horizontal Burning) ou UL94 V (Vertical Burning). O método usado para foi o UL94 HB o qual o objeto é testado em posição horizontal em face da chama.

È utilizado esta norma com objetivo de classificar o biopolímero de fécula de mandioca com a UL94 HB através da velocidade de queima do material. Neste ensaio, realizado no Laboratório de Mecânica dos Fluidos NTI/UFRN, utilizaram-se 4 amostras, onde duas usavam retardante a chama e as outras duas não. Com Isso, este ensaio tem como objetivo verificar se o material é inflamável e constatar a influência do retardante a chama na inflamabilidade do material.

A chama deve ser aplicada na extremidade livre da amostra, marcação de $6 \mathrm{~mm}$, por um período de 30 segundos. Se o corpo de prova continuar a queimar após a remoção da chama, deve ser registrado o tempo necessário para a combustão atingir a marca de $25 \mathrm{~mm}$ e, se a 
combustão prosseguir, registrar o tempo necessário para a combustão atingir a marca de 100 $\mathrm{mm}$. Se a marca de $100 \mathrm{~mm}$ não for atingida, registrar o tempo e o comprimento danificado.

Neste ensaio utilizaram-se amostras com comprimento de $125 \mathrm{~mm}$ de comprimento, $13 \mathrm{~mm}$ de largura e $3 \mathrm{~mm}$ de espessura. As amostras foram marcadas a $6 \mathrm{~mm}$, a $25 \mathrm{~mm}$ e a $100 \mathrm{~mm}$ da extremidade a ser queimada. As amostras foram fixadas no gancho pela extremidade livre de marcação, com seu eixo longitudinal colocado na posição horizontal. O bico de Bunsen deve estar inclinado a um ângulo de $45^{\circ}$ e ajustado de modo a produzir uma chama azul de comprimento igual a $20 \mathrm{~mm}$ na posição vertical. A Figura 7 apresenta o ensaio de inflamabilidade em sua execução.

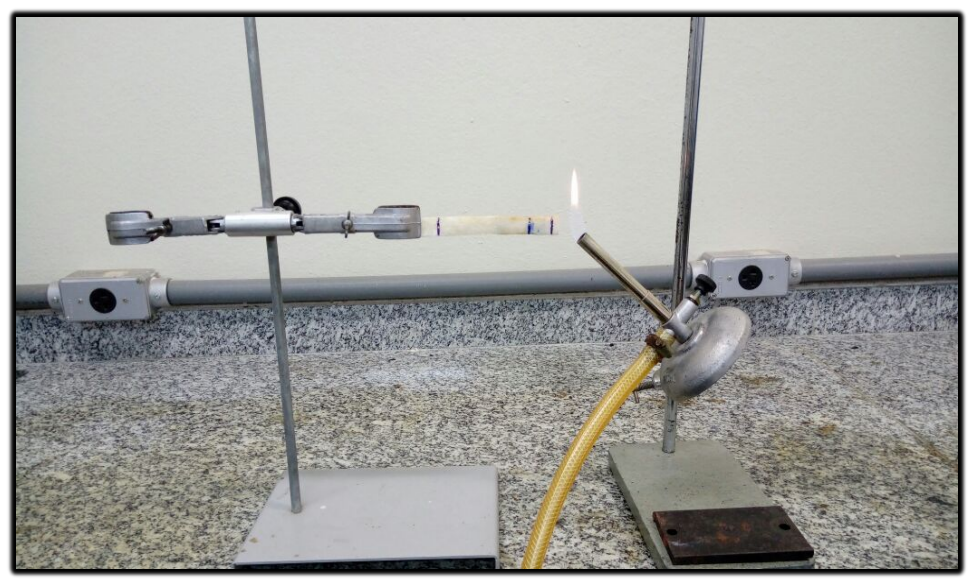

Figura 7: Ensaio de inflamabilidade

\section{RESULTADOS E DISCUSSÕES}

\subsection{Massa específica}

O resultado médio das amostram foram de $0,6692 \mathrm{~g} / \mathrm{cm}^{3}$, ou seja, $669,20 \mathrm{~kg} / \mathrm{m}^{3}$. Caracterizando-se como um material leve. O conhecimento da massa específica dos materiais é de fundamental importância, pois influência no peso total do sistema o qual o material é aplicado. Como parâmetro comparativo, a Figura 8 apresenta a densidade de alguns materiais usados em isolamento térmico que são disponíveis comercialmente.

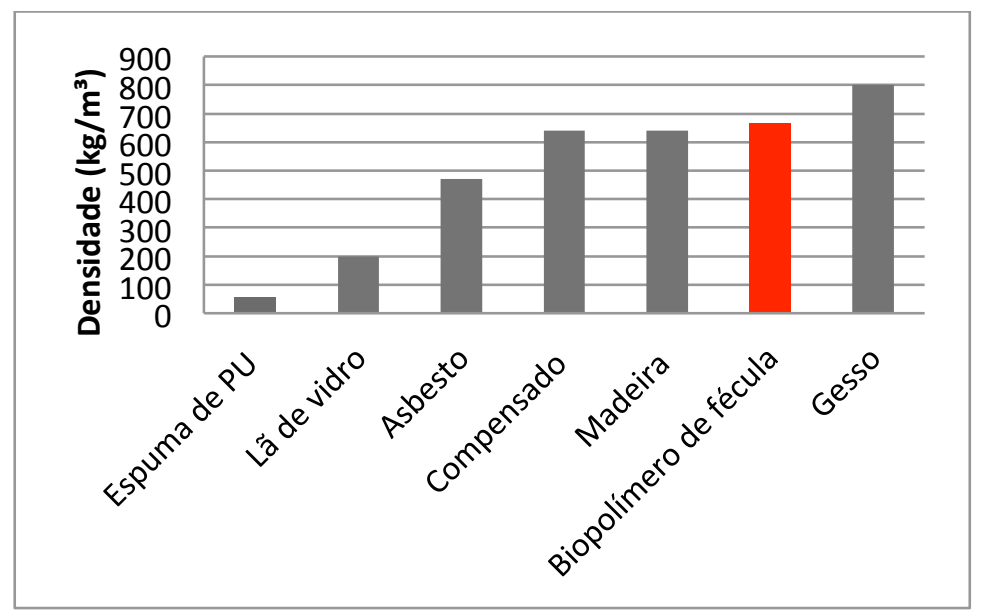

Figura 8: Comparação com alguns isolantes térmicos 
O biopolímero produzido tem características de uma espuma, mas comparada à espuma de poliuretano, possui uma densidade maior. Porém tem sua densidade próxima a da madeira e inferior a do gesso, os quais são materiais considerados isolantes térmicos. Dessa forma, o biopolímero desenvolvido é relativamente leve e tem sua densidade dentro da faixa dos materiais considerados isolantes, facilitando seu uso em aplicações apropriadas.

\subsection{Propriedades termofísicas}

Os valores médios das propriedades térmicas do material são: condutividade térmica 0,152 $\mathrm{W} / \mathrm{mK}$, resistividade térmica $686,529{ }^{\circ} \mathrm{C} . \mathrm{cm} / \mathrm{W}$, calor específico $1,210 \mathrm{MJ} / \mathrm{m}^{3} \mathrm{~K}$, difusividade térmica $0,125 \mathrm{~mm}^{2} / \mathrm{s}$.

\subsubsection{Condutividade térmica}

A condutividade térmica é uma das propriedades mais importantes dos isolantes térmicos, seu valor médio é de 0,152 W/mK para o polímero natural (biopolímero). A Figura 9 apresenta uma comparação entre as condutividades de materiais isolantes.

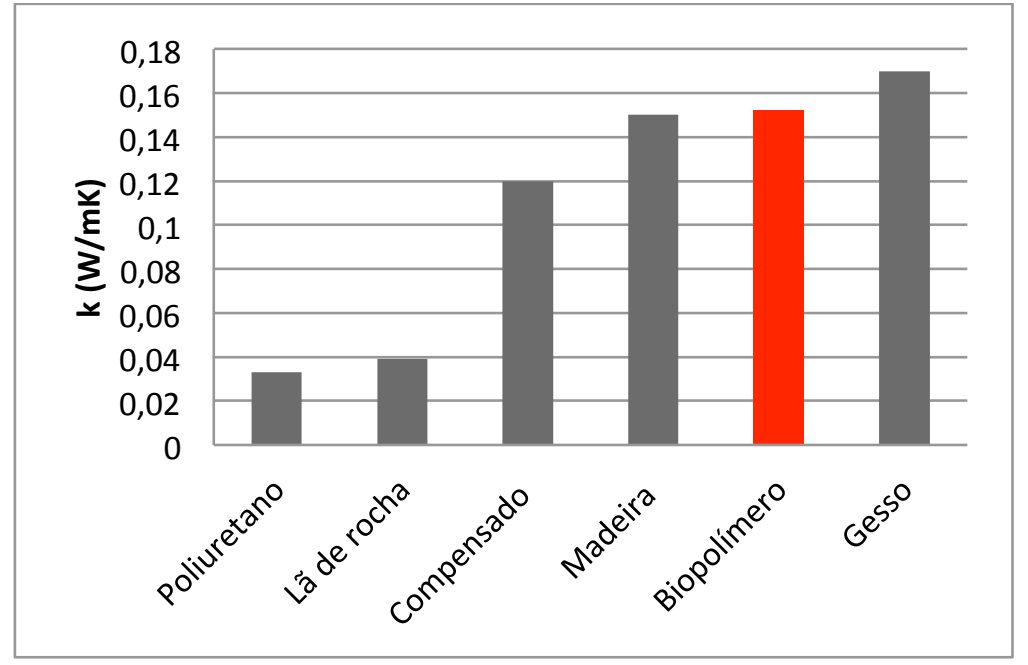

Figura 9: Condutividade térmica de materiais isolantes

Com relação aos resultados da condutividade térmica, quanto menor o valor obtido melhor será a propriedade de isolamento térmico do material. Através de uma análise comparativa entre os materiais isolantes térmicos apresentados na Figura 9, pode-se afirmar que o biopolímero de fécula de mandioca possui valores de condutividade térmica próximas as do asbesto, Madeira, compensado e gesso. Dessa forma, pode-se afirmar que o mesmo possui um valor de condutividade térmica que o classifica como isolante térmico.

O biopolímero de fécula de mandioca possui valor de condutividade térmica similar a materiais que são usados, principalmente, na construção civil, isso viabiliza seu uso em aplicações semelhantes. Diante disso, percebe-se que o biopolímero de fécula de mandioca possui uma vasta área de aplicações em isolamento térmico, pois se trata de um material com baixa condutividade térmica e, principalmente, por ser um material biodegradável. 


\subsubsection{Calor específico}

O material apresenta um valor de calor específico médio de $1,210 \mathrm{MJ} / \mathrm{m}^{3} \mathrm{~K}$. A Figura 10 apresenta uma análise comparativa entre os valores dos calores específicos de alguns materiais que são aplicados em isolamentos térmicos.

Os resultados mostraram que o material possui calor específico próximo aos da cortiça. Diante disso, é possível que o polímero natural possua aplicações semelhantes a esse, o qual é usado em isolamentos térmicos. Portanto, o biopolímero de fécula de mandioca possui um valor de calor específico próximo a dos isolantes térmicos disponíveis comercialmente, isso o classifica como um material isolante.

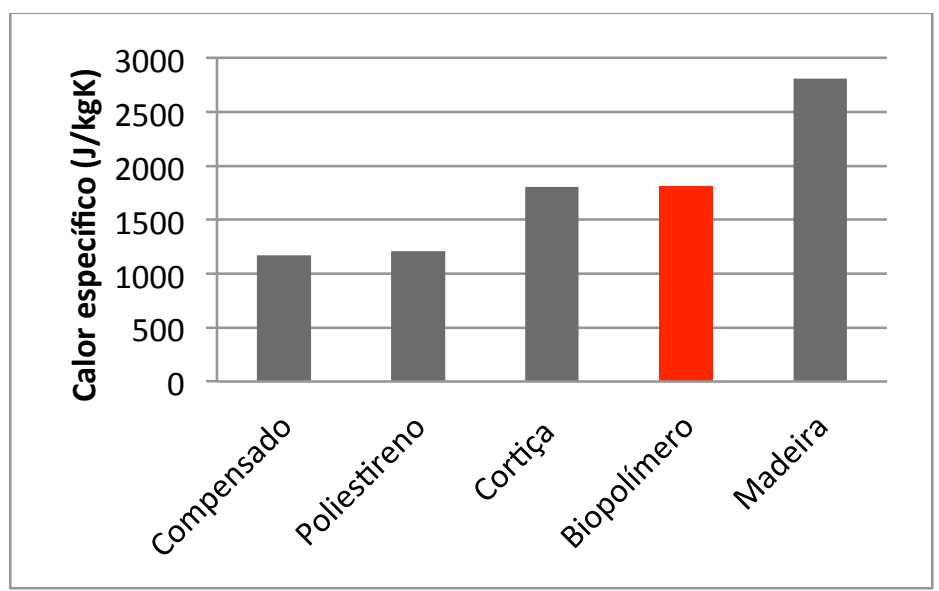

Figura 10: Calores específicos de materiais isolantes

\subsubsection{Difusividade térmica}

O material apresenta um valor médio da difusividade térmica de $0,125 \mathrm{~mm}^{2} / \mathrm{s}$. A Figura 11 apresenta os valores dessa propriedade de alguns materiais que são considerados isolantes térmico.

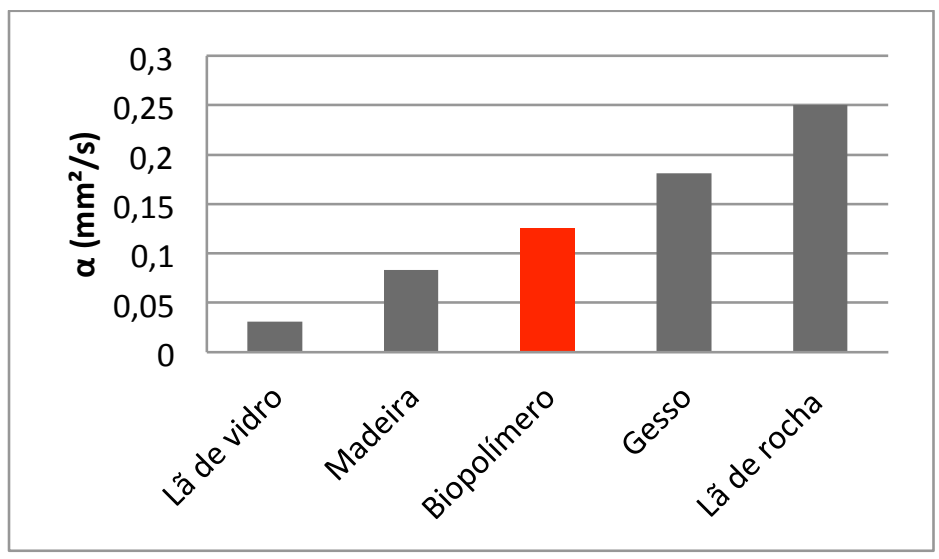

Figura 11: Difusividade térmica de materiais isolantes

Esses baixos valores expressam bem (como definido pela equação da difusividade térmica) a pouca capacidade de transferência de calor e a alta capacidade de armazenamento de energia por parte do biopolímero, habilitando-o a ser usado como material isolante térmico. Dessa 
forma, é possível que esse novo material possua aplicações semelhantes as dos produtos que possuem propriedades térmicas semelhantes (Madeira, asbesto e gesso).

\subsection{Dureza Shore D}

O biopolímero de fécula de mandioca apresenta um resultado médio de dureza de 57,5 ShD. A Figura 12 Apresenta um gráfico de dureza Shore D de alguns materiais que são usados como isolante térmico.

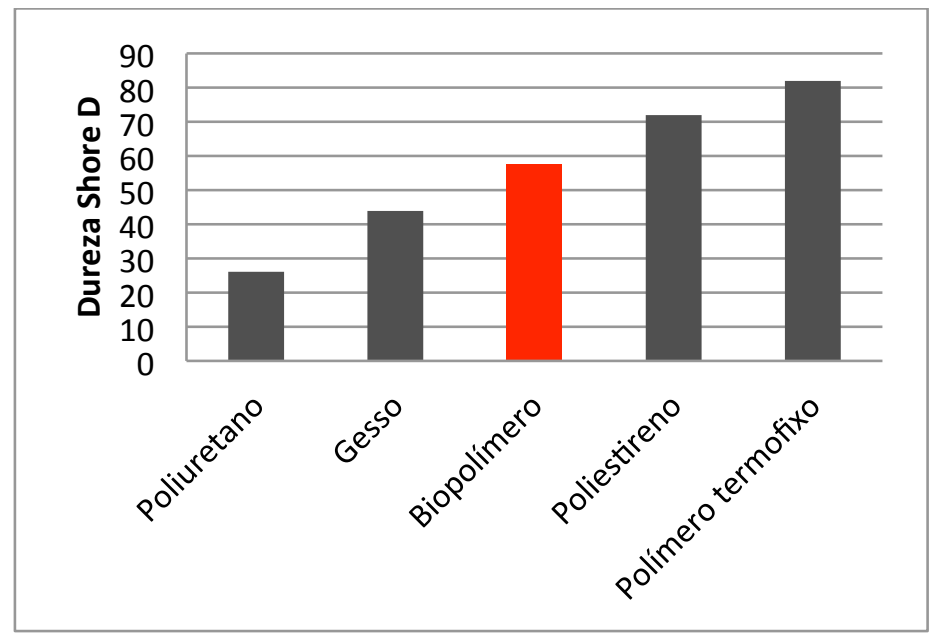

Figura 12: Valores de dureza de alguns isolantes térmicos

Através de uma análise comparativa pode-se notar que o biopolímero de fécula de mandioca possui um valor de dureza entre o poliestireno e o gesso. Quando o material é comparado com a espuma de poliuretano, pode-se constatar que o mesmo possui um valor de dureza aproximadamente duas vezes maior que a do poliuretano.

O poliestireno apresenta varias aplicações, podendo ser usado na fabricação de copos e talheres descartáveis, além de poder ser usado na forma expandida (Isopor) em isolamento térmico. Enquanto isso, o gesso é muito usado na construção civil em isolamento térmico de tetos e paredes. Com dureza semelhante a esses materiais, o biopolímero de fécula de mandioca pode ser usado em aplicações semelhantes. Dessa forma, esse material pode ser usado na fabricação de placas plana ou calhas de tubos, as quais são utilizadas para isolamento térmico.

\subsection{Analise termogravimétrica - TG}

A Figura 13 mostra a curva TG/DTG das duas amostras do biopolímero de fécula de mandioca. As curvas mostram as perdas de massa em duas etapas e os eventos térmicos correspondentes a essas perdas. As duas amostras apresentam perfis TG/DTG similares, confirmando a confiabilidade nos dados do ensaio.

A análise das curvas mostra que há uma perda de massa de aproximadamente $11 \%$ devido à desidratação associada a um pico endotérmico em torno dos $100^{\circ} \mathrm{C}$. A porcentagem de perda de peso nesta etapa depende do conteúdo de umidade contida no material. Segundo LIU et al. (2009), a temperatura inicial de degradação do amido não afeta o inicio da temperatura de decomposição, porque toda água se evapora antes. 


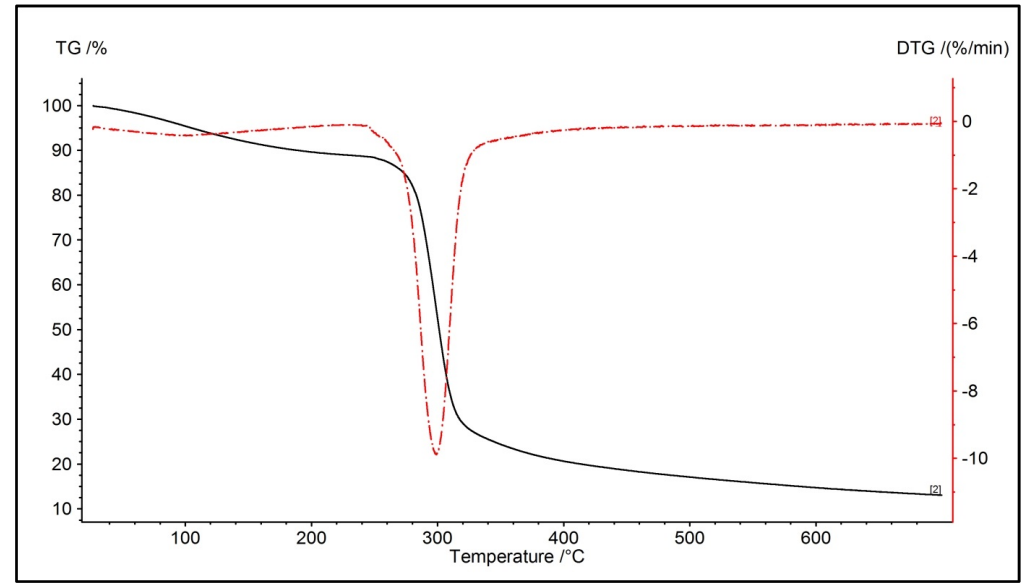

Figura 13: Curva TG/DTG do material

A decomposição térmica do biopolímero de fécula de mandioca começa após sua desidratação. De acordo com a Figura 13, a perda de massa total (\%) para o material foi de aproximadamente $88 \%$. O valor da temperatura de inicio da degradação térmica foi de aproximadamente $270{ }^{\circ} \mathrm{C}$, já o valor de pico da DTG foi de $300^{\circ} \mathrm{C}$.

Diante dos resultados obtidos através das análises termogravimétricas (TGA), ficou evidenciado que o biopolímero de fécula de mandioca pode ser utilizado em sistemas quentes, com o limite de temperatura de até $270{ }^{\circ} \mathrm{C}$, tendo em vista a não ocorrência de degradação do material até esse valor de temperatura.

Esse limite de temperatura abrange a maioria das aplicações térmicas em baixa e média temperatura, utilizadas no âmbito doméstico, industrial e comercial (YOUNG; FREEDMAN, 2008).

\subsection{Microscopia eletrônica de varredura - MEV}

Na Figura 14 vê-se a morfologia do biopolímero de fécula de mandioca obtida por microscopia eletrônica de varredura (MEV), com aumento de 200x e 2000x. Pode-se observar por meio das micrografias (a) e (b), formação de poros fechados que são aglomerados de vazios, os quais tornam o material menos resistente devido às contrações de tensões entre os vazios. Por outro lado, esses vazios possuem influência direta na condutividade térmica do mesmo, pois neles há presença de ar confinado o qual diminui a condutividade térmica do material.

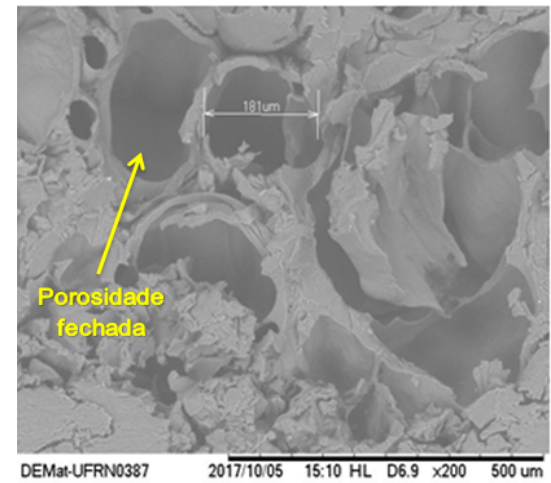

(a)

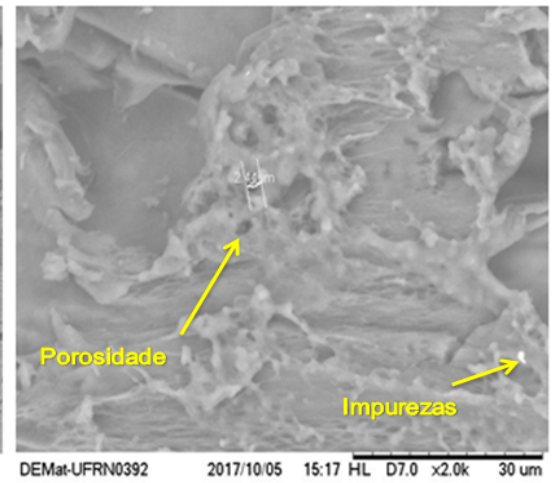

(b)

Figura 14: MEV - a) 200x; b) 2000x 
Percebe-se que há uma variação nas dimensões dos poros do material e que as concentrações desses poros são aleatórias, por exemplo, existem regiões com alta densidade de poros e outras com baixa, caracterizando o material como não uniforme.

Dessa forma, pode-se caracteriza o biopolímero de fécula de mandioca como um material leve, poroso e duro. Diante disso, o mesmo pode ser utilizado em varias aplicações na área térmica, devido possuir característica de um isolante térmico. Uma de suas aplicações como isolante térmico pode ser as placas de isolantes térmicos, usadas na construção civil para isolamentos de paredes, tetos e janela, ou pode ser utilizado como calha de isolamento térmico de tubos, muito usado em transmissão de vapor e sistemas de ar condicionado.

\subsection{Inflamabilidade}

Analisando os resultados, percebe-se que a velocidade de queima (velocidade da chama) é praticamente zero, ou seja, o material não entra em autocombustão. A Figura 16 mostra como foi à queima do material, o qual apresentou uma carbonização apenas na região superficial onde houve o contato direto da chama com o material. Dessa forma, não houve a deterioração do material, mostrado que o mesmo não entra em autocombustão, portanto, classificando-o como não inflamável.

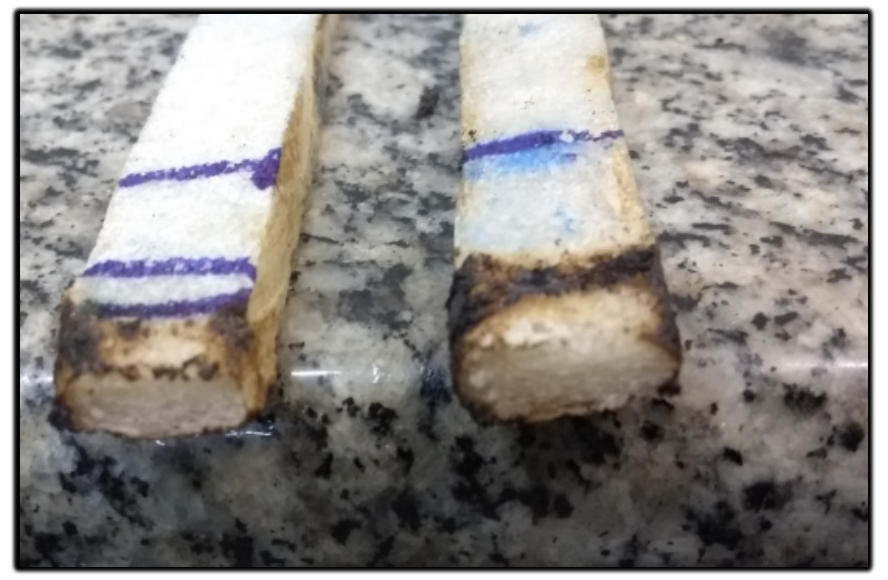

Figura 15: Resultado do ensaio de inflamabilidade

Como pode ser visto na Figura 15, não houve degradação do material. O centro do biopolímero de fécula de mandioca não chegou a queimar, mostrando que o material não é inflamável. Percebe-se que o uso do retardante não possui uma influência significativa na autocombustão do material, pois com o uso do mesmo, apenas a carbonização superficial foi menor.

Observou-se que mesmo durante o tempo de sustentação da chama, em todos os provetes analisados, não ocorria à emissão de fumaça e fuligem, tão pouco, o gotejamento de líquido escuro. Essas são características de polímeros derivados de petróleo. Dessa forma, o biopolímero de fécula de mandioca se mostra como um excelente material, o qual não é poluente, além de ser biodegradável. Portanto, possui propriedades térmicas semelhantes a isolantes térmicos disponíveis comercialmente. Por isso, o material se mostra viável em aplicações de isolamento térmico. 
Diante disso, pode-se concluir que o biopolímero de fécula de mandioca pode obter classificação segundo a norma UL-94 HB, que prescreve que a máxima velocidade de queima não deve ser superior a $38 \mathrm{~mm} / \mathrm{min}$, para provetes com espessuras compreendidas entre 3 e $13 \mathrm{~mm}$.

\section{CONCLUSÕES}

De acordo com os parâmetros térmicos analisados, pode-se afirmar que o biopolímero de fécula de mandioca pode ser utilizado como isolante térmico, uma vez que os valores encontrados nestes parâmetros são compatíveis com os de isolantes térmicos convencionais. Conclui-se que o biopolímero de fécula de mandioca constitui-se de um isolante térmico de caráter inovador, demostrando-se eficiente na retenção de calor.

Quanto à massa específica, conclui-se que o biopolímero de fécula de mandioca possui valores próximos a de isolantes térmicos disponíveis comercialmente, principalmente com a madeira e o gesso. Dessa forma, o material se caracteriza como leve, podendo abranger uma vasta área de aplicações. Quanto a dureza Shore $D$, verificou-se que o biopolímero de fécula de mandioca apresentou dureza de 57,5 ShD. Dessa forma, conclui-se que esse valor classifica o material como duro.

Através da analise termogravimétrica, conclui-se que o mesmo pode ser aplicado em sistemas quentes de até $270{ }^{\circ} \mathrm{C}$, colaborando com a questão ambiental, pois se trata de um material biodegradável.

A microscopia eletrônica de varredura apontou um material bastante poroso, com inúmeras cavidades e uma estrutura que se repete. Quanto à inflamabilidade, em função dos resultados obtidos, pode-se afirmar que o biopolímero de fécula de mandioca trata-se de um material não inflamável. Portando, o Biopolímero de fécula de mandioca pode ser classificado como um isolante térmico.

\section{AGRADECIMENTOS}

A Universidade Federal Do Rio Grande do Norte (UFRN) / Departamento de Engenharia mecânica (DEM) / Laboratório de Mecânica dos Fluidos (MECFLU) / Capes e CNPq pelo auxilio financeiro.

\section{REFERÊNCIAS}

ABD EL-REHIN, H. A. Characterization and possible agricultural application of polycrylamide/sodium alginate crosslinked hydrogels prepared by ionizing radiation. J. Appl. Polym. Sci., v. 101, n. 6, p. 3572-3580, 2006.

ASTM C177. Standard Test Method for Steady-State Heat Flux Measurements and Thermal Transmission Properties by Means of the Guarded- Hot-Plate Apparatus, 1997.

ASTM D 2240. Standard Test Methoud for Rubber Property - Durometer Hardness. 2003.

ASTM D 792. Standard Methouds for Density and Specific Gravity (Relative Density) of plastics by Displacement. 2008. 
AVÉROUS, L.; DIGABEL, F. L. Properties of biocomposites based on lignocellulosic fillers. Carbohydrate polymers. V. 66, p. 480-493, 2006.

BRITO, G. F.; AGRAWAL, P.; ARAÚJO, E. M.; MÉLO, T. J. A. Biopolímeros, polímeros biodegradáveis e polímeros verdes. Revista eletrônica de materiais e Processos, v.6.2, 127- 139, 2011.

DEBIAGI, F.; IVANO, L. R. P.F.M.; NASCIMENTO, P. H. A.; MALI, S. Embalagens biodegradáveis de amido reforçadas com fibras lignocelulósicas provenientes de resíduos agroindustriais. BBR Biochemistry and Biotechnology Reports, v. 1, n. 2, p. 57-67, 2013.

GALVÃO, A. C. P. Obtenção e caracterização de um compósito de poliuretano de mamona e pó de vidro para aplicações em isolantes térmicos. Dissertação de mestrado do Programa de PósGraduação em Engenharia Mecânica (PPGEM) - Universidade Federal do Rio Grande do Norte - UFRN, 2014.

KREITH. F. Princípios de transmissão de calor. 9. Ed. São Paulo: Editora Edgard Blucher, 2008.

MA, W.; TANG, C. H.; YIN, S. W.; YANG, X. Q.; WANG, Q.. LIU, F.; WEI, Z. H. Characterization of gelatin-based adible fi Ims incorporated with olive oil. Food Res. Int., v. 49, n.1, p. 572-579, 2012.

NAIME, N.; BRANT, A. J. C.; LUGÃO, A. B.; PONCE, P. Espumas de fécula de mandioca com fibras naturais. 20 CBECIMAT, 2012.

PEROTTI, G. F.; KIJCHAVENGKUL, T.; AURAS, R. A.; CONSTANTINO, V. R. L. Nanocomposites Based on Cassava Starch and Chitosan-Modified clay: Nanocomposites Based on Cassava Starch and Chitosan-Modified Clay: Physico-Mechanical Properties and Biodegradability in Simulated Compost Soil. J. Braz. Chem. Soc., Vol. 28, No. 4, 649-658, 2017.

RAMIREZ, M. G. L.; SATYANARAYANA, K. G.; IWAKIRI, S.; MUNIZ, G. B.; TANOBE, V.; FLORESSAHAGUN, T. S. Study of the properties of biocomposites. Part I. Cassava starch-green coir fibers from Brazil. Carbohydrate Polymers, v. 86, n. 4, p. 1712-1722, 2011.

RIYANJAN, S.; PATISAT, S. A Novel Packaging Film from Cassava Starch and Natural Rubber. Journal of Polymers and the Environment. 26:2845-2854, 2018.

STOFFEL, F.; WESCHENFELDER, E. F.; PIEMOLINI-BARROS, L. T.; ZENI, M. Preparação e caracterização de bandejas de espuma de amido de mandioca com quitosana e microcelulose. Revista Iberoamericana de Polimeros, v. 16, p. 260-266, 2015.

UL 94. Standard for Tests for Flammability of Plastic Materials for Parts in Devices and Appliances. 2013. 